\title{
CBRN Decontamination Tasks Supporting Rescue and Extraction Missions in CBRN Environment
}

\section{ABV-mentesítési feladatok ABV-környezetben végrehajtott mentés és kivonás támogatása során}

"Search and Extraction" is a NATO capability requirement without definition. The study shows the civilian search and rescue team requirements based on the Guidelines of the International Search and Rescue Advisory Group. A new definition is proposed: "Rescue and Extraction". In the main part of the study the problems of CBRN decontamination of vehicles, equipment and personnel during a Rescue and Extraction task are discussed.

Keywords: CBRN decontamination, Search and Rescue, Rescue and Extraction, INSARAG

A kutatás és kivonás NATO-képességkövetelmény, definíció nélkül. A tanulmány bemutatja a civil kutató-mentő csoportok követelményeit a Nemzetközi KutatóMentő Tanácsadó Csoport iránymutatásai alapján, továbbá egy új meghatározásjavaslatot alkalmaz, úgymint mentés és kivonás. A tanulmány fő részében a mentés és kivonás során a jármüvek, felszerelés és személyek $A B V$ mentesítésének problémáit tárgyaljuk.

Kulcsszavak: ABV-mentesítés, kutatás és mentés, mentés és kivonás, INSARAG 


\section{Foreword}

Regarding the dual use of military assets for both security and humanitarian/disaster relief purposes, one needs to understand the role of the military in modern societies. Large-scale disasters showed that military support was sometimes the turning point towards more effective relief efforts (e.g. Tsunami 2004/2005, Haiti earthquake 2010). Considering the collapsed buildings, there is only a minor difference between the consequences of an earthquake and, for example, bombing.

The North Atlantic Treaty Organization Military Committee identified the need for NATO to have the ability to conduct "Search and Extraction" missions to recover military and non-military personnel from a CBRN" environment. Neither the requirements for "Search and Extraction in a CBRN environment" nor the need to exploit unmanned systems in CBRN Rescue and Extraction are defined.

The terminology itself can cause misunderstanding, thus the meaning of the following words must be clarified: search, extraction, rescue, recovery. Several statements in this article are based on the outcome of the Search and Extraction Discovery Experiment workshop (6-7 November 2019) which was held in the Joint CBRN Defence Centre of Excellence in Vyskov, Czech Republic, and of which the author was the chairman.

Amongst the problems to be faced on the field regarding this activity, the essay focuses on the challenges posed by the different types of decontamination, therefore the detailed task organisation, additional equipment, capabilities, various additional supporting professionals such as guard-, EOD ${ }^{3}$, or MILENG ${ }^{4}$ subunits, or any affected non-governmental organisations will not be discussed in detail.

\section{General characteristics of urban search and rescue}

"The International Search and Rescue Advisory Group (INSARAG) is a global network of more than 90 countries and organisations under the umbrella of the United Nations. INSARAG deals with urban search and rescue related issues, aiming to establish minimum international standards for Urban Search and Rescue (USAR) teams and a methodology for international coordination in earthquake response, based on the INSARAG Guidelines endorsed by the United Nations General Assembly Resolution $57 / 150$ of 2002, on 'Strengthening the Effectiveness and Coordination of International Urban Search and Rescue Assistance'." [1]

The INSARAG Guidelines consist of three volumes. Volume I: Policy contains the methodology for USAR operations. Volume II: Preparedness and Response, with 3 manuals (A: Capacity Building, B: Operations, C: External Classification and Reclassification), provides procedures for USAR tasks and describes the standards for a USAR team. Training, readiness, classification and operations are also detailed in

\footnotetext{
Chemical, Biological, Radiological and Nuclear.

Explosive Ordnance Disposal.

Military Engineer.
} 
these volumes. Volume III: Operational Field Guide provides TTPs ${ }^{5}$ for tactical (field) level training sessions and missions.

The INSARAG Guidelines determine three types of USAR teams: light, medium and heavy, whose minimum capabilities are as follows:

\section{Light USAR teams}

"Light USAR teams have basic or minimal operational capabilities in terms of rescue equipment, knowledge and competencies, and do not necessarily all five key USAR components (management, search, rescue, medical and logistics). However, light USAR teams are usually able to assist with the surface search and rescue of victims in the immediate aftermath of a sudden-onset structural collapse disaster. Due to their limitations, light USAR teams do not partake in the INSARAG External Classification (IEC) process and therefore do not normally deploy internationally." [2: 20] There is no required decontamination capability, only identification and isolation of hazardous materials. They are able to follow the Emergency Response Guide (ERG).

\section{Medium USAR teams}

"A medium USAR team comprises the five components listed above and has the ability to conduct complex technical search and rescue operations in collapsed or failed structures of heavy wood and/or reinforced masonry construction, including structures reinforced and/or built with structural steel. They must also conduct rigging and lifting operations. A medium USAR team is expected to have the operational capability to work only at one worksite." [2: 20] According to the INSARAG guidelines, [3: 85] household chemical identification, isolation and gross decontamination is required.

\section{Heavy USAR teams}

"Heavy USAR teams comprise the five components listed above and have the operational capability for complex technical search and rescue operations in collapsed or failed structures, particularly those involving structures reinforced and/or built with structural steel." [2: 20] They must also conduct rigging and lifting operations. A heavy USAR team is expected to have the equipment and manpower to work in a technical capacity at two worksites simultaneously. Generally, an assignment of this sort would last longer than 24 hours. "Recognition and use of USAR team personal protective equipment," furthermore, "gross and technical decontamination procedures and systems" is required. [3: 86]

The INSARAG guidelines contain a paragraph about Hazardous Materials Operations, but there are no details of CBRN decontamination except general

Tactics, techniques and procedures. 
requirements, such as: "establishing decontamination sites - including the appropriate disposal of contaminated run-off, ensuring the decontamination of assigned tools and equipment, including protective clothing and ensuring the decontamination of assigned transportation vehicles." [4:75] The INSARAG guidelines refer to civil environment. Further details need to be defined regarding military activities due to the likely contamination of personnel, equipment and vehicles in a CBRN hazard area. Feasible decontamination procedures should be set up due to the special decontamination needs of casualties, life-saving-, and rescue equipment and vehicles. The rescue of non-military personnel is also a challenge; they are not aware of decontamination procedures; they do not have standard protective equipment and the language barrier can make communication difficult.

As an international example, disaster relief is an essential element of the Austrian Armed Forces' operational tasks. CBRN-defence forces, engineers and other military elements are a vital part of Austria's national disaster management system. Austrian Forces Disaster Relief Unit's (AFDRU) main tasks are the rescue of humans from life-threatening situations as well as lifesaving activities after natural or technical disasters ranging from earthquakes, chemical disasters to accidents in nuclear power plants. AFDRU's structure is modular. The team size and composition vary from scenario to scenario. For each deployment of AFDRU, the structure is tailored to the needs and the requirements in the affected country, but the main elements of the capability are: a CBRN reconnaissance platoon, a CBRN decontamination platoon, a USAR platoon (based on CBRN soldiers) and a water purification platoon. [5]

Hungary represents a different approach. USAR teams are subordinated to the National Directorate General for Disaster Management of the Ministry of Interior. The Hungarian National Organisation for Rescue Services (HUNOR) is a qualified heavy USAR team and the medium USAR capability is the Hungarian National Integrated Organisation for Rescue Services (HUSZAR). The Hungarian Defence Forces has 47 specialised teams designated to disaster management, but there is no USAR team.

As the scenario of "CBRN Rescue and Extraction" (as well as Rescue and Extraction in a non-contaminated area) can vary in scale, the only solution is to assemble a Task Force, which is to be tailored in accordance with the respective conditions. In the course of concept or doctrine development regarding "Rescue and Extraction" it has to be defined what components a "CBRN Rescue and Extraction Task Force" should consist of. In accordance with AJP 3.14 (A), ${ }^{6}$ NATO led forces have to be trained and capable to conduct light rescue [6: 4/9]. This capability can be assessed as a kind of "all arms" capability but does not go further than an initial capability. This also concurs with INSARAG light teams and lays the basis for a potential Task Force, but AJP 3.14 (A) (or any other NATO documents) do refer to medium or heavy teams as described in the INSARAG Guidelines.

In a CBRN environment the activity is supported by CBRN units, which have to include a CBRN decontamination capability as well.

6 Allied Joint Doctrine for Force Protection. 


\section{Terminology}

"Search and extraction" is not a NATO-agreed term and finding the appropriate meaning will lead to confusion. "Search and Rescue" is a NATO-agreed term and clearly identifies the needs: "The use of aircraft, surface craft, submarines, specialized rescue teams and equipment to search for and rescue personnel in distress on land or at sea." [7: 114] It does not exclude the mission in a CBRN environment either. Additionally, looking at this term from a comprehensive approach, "Search and Rescue" is a commonly used term in INSARAG Guidelines [2: 4] which are mainly about USAR and are focused on the deployment of troops specially equipped for rescuing people after earthquakes in a mostly peaceful environment.

Considering the current terminology, a new term must be found for the activity of "rescuing and extracting personnel out of a CBRN contaminated area" by the JCBRN Defence Capability Development Group (JCBRND CDG) Doctrine and Terminology Panel. The proposed term to be defined is: "CBRN Rescue and Extraction". This "CBRN Rescue and Extraction" should be a specific case of "Rescue and Extraction". Subsequently, the adjustment of the related $\mathrm{AJP}^{7} \mathrm{~s}$ and $\mathrm{ATP}^{8} \mathrm{~S}$ should be initiated by JCBRND CDG and the nations should make the adjustments.

\section{CBRN decontamination requirements and responsibilities during a CBRN rescue and extraction mission}

According to NATO, AJP-3.8, "Hazard management is an enabling component where forces seek to avoid contamination, recover personnel, regenerate equipment and restore infrastructure to maintain or re-establish operational tempo and effectiveness" [8: 2/9]. Hazard management consists of pre-CBRN incident and post-CBRN incident measures. Keeping in mind the fundamental rule, the aim is not the elimination of the hazard but hazard management.

Use of CBRN weapons creates unique residual hazards that may require decontamination. In addition to the deliberate use of these weapons, collateral damage, natural disasters and industrial emissions may also require decontamination. "Against the background of the increasing number of terrorist attacks, effective CBRN defence is of principal importance for the armed forces as well as for civil defence and disaster management units." [9: 26]

\section{Immediate decontamination}

If prevention fails, a CBRN event occurs, we face the challenge of contamination and, as a first step, immediate decontamination is needed. 
Immediate decontamination can be carried out by every soldier upon becoming contaminated and may include decontamination of some personal clothing and/ or equipment. The aim of immediate decontamination is "to save lives, minimise casualties and limit the spread of contamination; nevertheless personal protection must be sustained." [10: 10/18] Immediate decontamination will be conducted right after the skin (or the equipment mentioned above) has been contaminated. The responsibility to conduct it is every soldier's duty. This responsibility requires proper knowledge and useable, effective decontamination equipment. Acceptable response by the soldiers in case of contamination cannot be conducted without the knowledge of the immediate decontamination procedure, therefore the CBRN defence survival standards of proficiency for non-CBRN specialists, ATP 3.8.1. VOL III. ${ }^{9}$ requires "carrying out an immediate individual decontamination drill and non-specialists must be able to recognise or detect chemical agent contamination and perform immediate personal decontamination of skin, clothing, personal equipment, individual weapon and position, vehicles and crew-served equipment." [11:2/3]

If soldiers are in a situation where they need to be rescued and extracted, the circumstances are more difficult. The movement of the soldiers might be limited, the immediate decontamination kit may be out of reach, but their survival depends on the appropriate use of the IPE ${ }^{10}$ and on immediate decontamination. These circumstances emphasise the importance of CBRN training.

Rescue and extraction personnel have a dual task regarding immediate decontamination. They have to be able to carry out their own immediate decontamination. Beyond this, they are responsible for the immediate decontamination of the rescued and extracted personnel if they are unable to do so themselves, because they do not have an immediate decontamination kit (in case of non-military personnel as well) or because the rescued/extracted person is unconscious. That means they have to be aware of the contamination of the rescued/extracted person and should have an additional decontamination kit for this kind of a situation.

The next question is time management. Conducting immediate decontamination in a CBRN hazard area may save the life of the decontaminated person but might pose a risk to the lives of both the other rescued/extracted person(s) and the lives of the rescuing/extracting personnel. The rescue/extraction personnel have to wear IPE and the other rescued persons can receive both gas masks and chemical splash covers or even regular IPE if they are not protected, but a confirmed contaminated person cannot be left without decontamination.

\section{Operational decontamination}

The aim of operational decontamination is "to remove or neutralize contaminants from the equipment, crew-served weapons, and vehicles that must be used by the unit in the execution of its operational role, in order to limit the spread of contamination."

\footnotetext{
Allied Tactical Publication, CBRN defence standards for education, training and evaluation (April 2011).

10 Individual Protective Equipment.
} 
[10: 10/18] Usually operational decontamination is a procedure where the tires and those parts of the vehicle are decontaminated which need to be touched by the crew during the operation. It also includes the decontamination of the worn IPE (gloves, boots, masks).

When discussing operational decontamination, it is obvious that during a rescue and extraction task the only objects of it are the vehicles of the search and rescue team arriving from the hazard area and preparing for the next entry. We have to ask the question: is time-consuming (even minutes can cost lives) decontamination worth the delay? The rescue team is under time pressure and without doubt, the vehicle (either aerial or ground vehicle) will go back into the contaminated area immediately after decontamination. I recommend not dealing with this decontamination phase, or at least examining whether it is necessary.

For the handover/takeover of the rescued and transported persons an exchange zone has to be set up. This type of exchange zone is described in detail in ATP-88 Ed.A(1) ${ }^{11}$ [12:3/4], but the main principle applies to ground vehicles as well. The vehicle moves between the contaminated area and the exchange zone and both the crew and the vehicle will only be decontaminated after the completion of the task. The exchange zone has to be outside the hazard area but in the dirty part of the decontamination site and has to have a controlled road connection with the pre-decontamination staging area of the decontamination site. To designate the same area for staging and exchanging may cause confusion among the waiting troops due to vehicle movement, the transportation of the deceased and the casualties on various other routes, and therefore it is not recommended. In addition, if the transportation is done by an aerial vehicle, the idea of the common area is even worse.

\section{Thorough decontamination}

\section{Personnel decontamination}

After immediate decontamination, personnel decontamination is needed to prevent the loss of soldiers or non-military personnel. Before the discussion of personnel decontamination another fact has to be taken into consideration, namely the procedure in case of casualties.

There are two types of methods regarding this issue: the "scoop and go" and the "stay and play" methods.

The basic difference is the place of the treatment. According to the "scoop and go" method, injured people are collected and, after a short emergency treatment if necessary, they are transported to medical facilities. Basically, the patient is transported to the doctor. According to the "play and stay" method the procedure is vice versa, the doctor is transported to the injured who receives medical treatment on the spot. [13: 188]

11 Allied Tactical Publication 88 Edition A (1) Chemical, Biological, Radiological, Nuclear (CBRN) hazard management for airlift operations. 
During a "rescue and extraction" mission, the methods used change in the different phases of the mission. In the hazard area, during the lifesaving phase the "scoop and go" policy has to be followed. It does not make sense to risk the lives of the medical personnel by taking them into the hazard area and it is not reasonable to spend there more time than necessary. However, CBRN contaminated personnel cannot be transported to any medical facility without decontamination.

A decontamination site is needed outside the hazard area. ${ }^{12}$ Every person (it does not matter whether military or civilian, own troops, allies or neutral) has to be decontaminated if the situation allows.

Medical personnel support the personnel decontamination even in case of no casualties. When the decontamination unit prepares for the support of a rescue and extraction mission, the probability of there being wounded personnel is higher and therefore higher standard medical support is needed. These medical personnel have to be prepared to conduct medical triage. In case of mass casualties, decontamination triage is also needed to reduce the pressure on the decontamination line. This decontamination triage has to be conducted in the dirty place of the decontamination site. Before decontamination it may be necessary to provide emergency medical treatment.

General decontamination sites consist of a personnel decontamination station and several vehicle and equipment decontamination stations, but they are not automatically prepared for casualty decontamination.

The approaches of nations to casualty decontamination are different, ${ }^{13}$ but the statement of the AJP-3.8 is clear: "Medical forces are responsible for CBRN casualty $\mathrm{HM},{ }^{14}$ including procedures for the decontamination of casualties." [8: 2/10] When the task is rescue and extraction from a CBRN hazard area, the probability of many contaminated deceased personnel is high. They have to be decontaminated after the casualty decontamination is done. Out of reverence the deceased have to be decontaminated in the casualty decontamination station operated by medical personnel.

\section{Equipment decontamination}

A regular decontamination site has the capability to decontaminate both general and sensitive equipment. The existing procedures provide adequate solutions to conduct these subtasks. Sensitive equipment decontamination is still a challenge, but there are several solutions to do it in a sufficient way. ${ }^{15}$ What needs to be examined is the special rescue equipment. For example, contaminated ropes used during rescue in a CBRN hazard area should not be decontaminated. There is no prewritten recipe

12 The decontamination site is divided into a clean and a dirty part, but the whole decontamination site has to be set up in an originally non-contaminated place.

13 For example, in Hungary the CBRN battalion has equipment to decontaminate wounded personnel.

14 Hazard management.

15 Plasma technologies (the use of ionized gas, made by discharge or electric arc, to destroy biological and to some extent chemical agents by oxidation) or vacuum technology (the use of extremely high vacuum and radiant heat to decontaminate chemical agents, while nebulised disinfectant is used for bio agents). 
for what has and what does not have to be decontaminated after the task has been completed; it is decided based on the situation. The main principle should be to have the courage to decide to destroy the equipment and cause loss of equipment rather than causing loss of personnel.

\section{Vehicle decontamination}

The decontamination site must ensure the decontamination of the vehicles of the rescue and extraction team and those vehicles that come out of the hazard area.

In the case of ground vehicles, the general procedures of the decontamination unit can be applied. The challenge is the decontamination of an aerial vehicle.

General caustic decontaminants corrode metal, rubber and plastic. Non caustic decontaminants should be used or can be substituted for with soap and water, kerosene or diesel fuels. [14: 7/2]

Even though, due to the speed of these vehicles and the rotor airflow, the evaporation rate increases in the exterior of the vehicle, there are remaining agents. During a rescue and extraction task the interior is expected to be contaminated as well, so flying out from the hazard area with open doors may increase the evaporation. New contamination during the flight is not likely owing to the air stream and the altitude.

The area of the aerial vehicle (helicopter) decontamination station has to be chosen wisely. There are several options:

1. The vehicle (and the crew) is decontaminated in a previously used decontamination site close to the area of the task.

- Advantage: Already set up decontamination infrastructure, there is no loss of time.

- Disadvantage: The surface has to be appropriate for the movement of the vehicle on the ground from the landing point to the decontamination station. The vehicle cannot land at the decontamination station because of contaminated equipment and water collection points which are already there.

2. The vehicle is decontaminated at a new decontamination station on the same site as was used during the execution of the task.

- Advantage: There is no previously contaminated decontamination station so the helicopter can land at or very close to the place of decontamination. If the capability of the supporting decontamination unit allows, the decontamination station should be prepared ahead of the need for decontamination and thus the loss of time is avoided.

- Disadvantage: Due to the landing helicopter, the vehicle decontamination station has to be set up at a safe distance both from the personnel decontamination station, which necessitates a longer walk for the crew, and from the designated clear area of the decontamination site.

3. The vehicle is decontaminated at the landing point (exchange zone). The decontamination unit sets up and prepares itself for the decontamination after the vehicle has landed. 
- Advantage: Less chance of area contamination.

- Disadvantage: It is time-consuming and exhausting to set up a decontamination station in IPE and there is a high probability of the contamination of the vehicles, equipment and personnel of the supporting CBRN unit. This method has not been used recently.

4. The aerial vehicle is decontaminated in a distance from the area of operations on a well-prepared decontamination site by a different supporting unit.

- Advantage: The chosen decontamination site can have advanced infrastructure. The decontamination personnel are not exhausted, and not affected by the presence of the deceased and the casualties. During the movement at high speed, faster evaporation can be expected.

- Disadvantage: Cross contamination is likely.

\section{Conclusion}

Being capable of conducting proper immediate decontamination, having effective IPE and being able to use it are all vital to ensure survivability. From a CBRN decontamination point of view, rescue and extraction is a different task from general decontamination. In case of contamination of rescue personnel, casualties, deceased, the exterior and the interior of a helicopter or a ground vehicle, the decontamination is not basic level task. Automatism, patterns or templates cannot be used, because every situation is different. There is a need to find milder systems for the decontamination of operational critical equipment. For the decontamination of the deceased, psychological preparation of the decontamination personnel is needed. There is also a need to find systems which can work in case of both trauma patients and CBRN agent contamination.

The subject matter experts of the Hungarian Defence Forces CBRN and Special Operations Forces (SOF) have been working on the feasible and suitable CBRN support of different levels of SOF units. Rescue and Extraction tasks (considering personnel recovery tasks as well) from a CBRN hazard area form part of the possible cooperation, therefore the elaboration of the details is an interdisciplinary responsibility (involving other professionals as well, like the members of the recommended TF).

There is place for improvement. The transformation of NATO results in new requirements, and these requirements are becoming more and more complex. Professions and organisations, irrespective of whether they are supporting or supported, force users, force providers or force developers, have to examine the limits of their capabilities and revise their thinking in order to explore new areas.

\section{References}

[1] "International Search and Rescue Advisory Group," International Search and Rescue Advisory Group. [Online]. Available: www.insarag.org. [Accessed Oct. 10, 2019].

[2] International Search and Extraction Advisory Group, "INSARAG Guidelines Volume I: Policy," International Search and Extraction Advisory Group, 11 February 
2015. [Online]. Available: http://portal.undac.org/pssuportal/portalrest/filesharing/ download/public/9aapqmXeE4G5bvo. [Accessed Apr. 22, 2020].

[3] International Search and Rescue Advisory Group, "INSARAG Guidelines Volume II: Preparedness and Response Chapeau Manual A: Capacity Building." International Search and Rescue Advisory Group, 11 Febr. 2015. [Online]. Available: http://122.155.1.141/site2/cms-download_content.php?did=22849. [Accessed Oct. 10, 2019].

[4] International Search and Rescue Advisory Group, "INSARAG Guidelines Volume III: Operational Field Guide," International Search and Rescue Advisory Group, 11 Febr. 2015. [Online]. Available: http://portal.undac.org/pssuportal/portalrest/ filesharing/download/public/Ol1DBdLbNVts5oB. [Accessed Apr. 21, 2020].

[5] Presse- und Informationsdienst des BM für Landesverteidigung, "Austrian Forces Disaster Relief Unit," Presse- und Informationsdienst des BM für Landesverteidigung, 11 July 2001. [Online]. Available: https://web.archive.org/web/20010711021055/http:/ www.bundesheer.gv.at/organisation/beitraege/abcabws/english/org_s3_abcab_eng_afdru. shtml. [Accessed Febr. 25, 2020].

[6] NATO, AJP-3.14, Allied Joint Doctrine for Force Protection, NATO Standardization Office, 2015.

[7] NATO, AAP-06 Edition 2019 NATO Glossary of Terms and Definitions, NATO Standardization Office, 2019. [Online]. Available: https://standard.di.mod.bg/pls/mstd/ MSTD.blob_upload_download_routines.download_blob?p_id=281\&p_table_name $=d_{\text {_ }}$ ref_documents\&p_file_name_column_name=file_name\&p_mime_type_column_name=mime_type\&p_blob_column_name=contents\&p_app_id=600. [Accessed Apr. 21, 2020].

[8] NATO, AJP-3.8 Allied Joint Doctrine for Comprehensive Chemical, Biological, Radiological and Nuclear Defence (Edition B), NATO Standardization Office, 2018.

[9] S. Szabó, L. Földi and T. Berek "Latest CBRN decontamination technology at the Hungarian Defence Forces" Hadmérnök, Vol. 7, No. 4, December 2012, pp. 25-37. [Online serial]. Available: http://hadmernok.hu/2012_4_szabo_foldi_berek. pdf [Accessed Febr. 25, 2020].

[10] NATO, ATP-3.8.1. VOL I, CBRN Defence on Operations, Volume I., NATO Standardization Agency, 2010.

[11] NATO, ATP-3.8.1. VOL III, CBRN Defence Standards for Education, Training and Evaluation Volume III., NATO Standardization Agency, 2011.

[12] NATO, ATP- 88 Edition A (1) CBRN Hazard Management for Airlift Operations, NATO Standardization Office, 2015.

[13] R. C. Reed and S. Bourn, "Prehospital Emergency Medicine - UK Military Experience," BJA Education 18 (6), 28 March 2018, pp. 185-190. [Online]. DOI: https:// doi.org/10.1016/j.bjae.2018.03.003

[14] Headquarters Department of the Army and Commandant United States Marine Corps, FM 3-5/MCWP 3-37.3 NBC Decontamination, United States: HQ TRADOC, 2002. [Online]. Available: www.hsdl.org/?view\&did=776413. [Accessed Apr. $22,2020]$. 